\title{
Vaivém das marés: o dia a dia dos trabalhadores catraieiros no porto de Fortaleza(1903-1904)
}

Nágila Maia de Morais

Resumo: O presente artigo busca analisar o dia a dia de trabalho dos catraieiros no Porto de Fortaleza, em 1903-1904, depois de uma greve e da repressão aos manifestantes. Estes trabalhadores eram responsáveis por realizar o serviço de carga e descarga dos navios em pequenas embarcações, denominadas catraias. As relações que os catraieiros mantinham com os contratadores, homens ligados às grandes empresas comerciais, os quais contratavam mão de obra de maneira avulsa, serão abordadas mediante a constatação de como se constituíam as relações socioculturais de trabalho, bem como as disputas econômicas que as permeavam. A partir destas, procura-se compreender o cotidiano dos trabalhadores catraieiros, as formas e os valores do pagamento, para que se trilhe um caminho que conduza à compreensão das ações cotidianas desses homens no trato com o trabalho. Para tanto, foram utilizados como fonte o Jornal "Unitário", o "Jornal do Ceará" e a documentação comercial da Casa Boris.

Palavras-chave: Catraieiros, Greve, Trabalhadores

Abstract: This article examines the shifting nature the catraieiros' work on the port of Fortaleza, between 1903 and 1904, as a result of a violent strike that paralyzed the port. These workers were responsible for loading and unloading ships, using for such, small vessels called catraias. In this sense, the relationships between the catraieiros and their employers, (elites liked to the city's commercial enterprises, is an essential part of the equation. I will explore how hired workers in a loose way. To do so, I will exemine how socio-cultural and work relationships between workers and employers were established, as well as the ongoing economic conflict. My research draws on the newspapers "Unitário", "Jornal do Ceará" e the commercial files of Casa Boris.

Keywords: Catraieiros, strikers, workers.

\section{INTRODUÇÃO}

Na manhã de domingo, 3 de janeiro de 1904, os catraieiros paralisaram suas atividades e foram até o Galpão do Porto para protestar contra o sorteio, quando foram surpreendidos com a ação do Batalhão de Polícia do Estado. A polícia, ao promover a ação agressiva, matou 7 pessoas e feriu mais de 30, entre os manifestantes e curiosos que observavam o movimento ${ }^{1}$.

\footnotetext{
* Professora Mestre do departamento de História da Faculdade INTA (Instituto de Teologia Aplicada). nagilamaia@hotmail.com

${ }^{1}$ De acordo com a Lei Federal de Sorteio e Alistamento para a Armada do ano de 1875, Artigo 87, § 4으, os trabalhadores vinculados à capitania dos Portos, como catraieiros, pescadores e aprendizes marinheiros,
} 
Toda a alma cearense hontem se constrangiu de dor e tristesa, ante os cannibalescos sucessos, que produsiram montões de cadáveres. Muito sangue derramou-se de inocentes, e a cidade em peso se horrorizou diante da terrível mortandade sem exemplo na história do Ceará ou qualquer outro povo civilisado ${ }^{2}$.

A greve dos trabalhadores catraieiros é uma página importante para o movimento operário no Estado do Ceará, sendo uma das primeiras mobilizações de trabalhadores durante os primeiros anos da República. Analisar as ações cotidianas destes trabalhadores, no porto da cidade de Fortaleza, é essencial para compreender os fatores motivadores da mobilização.

As fontes utilizadas são baseadas na documentação da Casa Boris Frères, importante casa comercial instalada no Ceará com a vinda dos irmãos Alphonse e Theodore Boris, oriundos da província francesa de Lorena. Chegaram à cidade do Rio de Janeiro em 1865 e, em seguida, foram para Recife, vindo posteriormente a Fortaleza, em 1867. No ano de 1869, fundaram a casa de comércio Theodore Boris \& Irmãos, que tinha como principal atividade as permutas comerciais.

A Casa Boris possuía papel de destaque no comércio importador do Estado e mantinha relações estreitas com a oligarquia acciolina ${ }^{3}$. A Casa comercial foi responsável por incentivos financeiros e pela compra de materiais para a construção de obras públicas, bem como pela proposta para encampar o Porto, em $1904^{4}$.

Ao ponderar as notas de contratação de mão de obra para o transporte de mercadorias e passageiros, pode-se chegar até os catraieiros e entender a forma de contratação e o pagamento desses trabalhadores. Essa documentação comercial, referente aos anos de 1903 e 1904, trata do pagamento de trabalhadores que prestavam serviços de

deveriam ser inseridos no processo de sorteio. Durante o ano de 1903, foram assinados pelo Presidente da República do Brasil, Rodrigues Alves, os Decretos no 4.901 e n 4.983 , referentes ao processo de sorteio dos matriculados para a Armada da Marinha, com o objetivo de preencher os espaços vagos no contingente. 0 Decreto de $n=4.901$ expunha as instruções e a regulamentação para que os Sorteados, com idade de 16 a 30 anos, exceto maquinistas e pilotos, fossem inscritos por ordem alfabética em um livro especial, denominado Livro de Sorteio. Em 27 de dezembro de 1903 foi realizado o primeiro Sorteio em Fortaleza, pelo qual catraieiros e pescadores foram sorteados. Entretanto, ficaram insatisfeitos com o fato, pois, com a obrigação de servir à Armada, deveriam se afastar das suas famílias e do trabalho. Os trabalhadores iniciaram, então, as mobilizações e contaram com o apoio de políticos e advogados para fazer o pedido de habeas corpus.

2 FIRMEZA. Hermenegildo. Canibalismo. Unitário. Fortaleza. Instituto Histórico e Geográfico do Ceará, 4 de janeiro de 1904, no 79, p. 1.

${ }^{3}$ Oligarquia liderada por Antonio Pinto Nogueira Accioly, que teve papel de destaque na política cearense, principalmente entre os anos de 1896-1912.

${ }^{4}$ ANDRADE, João Mendes de. "Oligarquia Acciolina (1877-1930)". Dissertação de Mestrado defendida no Programa de pós-graduação em História - Universidade Federal de Pernambuco, 1986, p. 219. 
transporte de mercadorias para a Casa Boris. É possível compreender, ainda, a dinâmica do sistema de contratação de mão de obra avulsa do Porto de Fortaleza e a difícil rotina de trabalho dos catraieiros, embora com uma visão limitada, pois é analisado apenas um dos contratadores do Porto de Fortaleza 5 .

A batalha travada entre $O$ Unitário, o Jornal do Ceará e a oligarquia acciolina reflete a disputa pela "conquista dos corações e mentes" dos cearenses durante o período estudado.

Para melhor compreender o cotidiano dos catraieiros foram utilizados os memorialistas e a literatura do período, através dos romances $A$ Afilhada ${ }^{6}, \mathrm{O} \mathrm{Mississipi}^{7}$ e A Normalista. $^{8}$

A literatura tornou-se fundamental para a pesquisa ao retratar o cotidiano dos trabalhadores do porto, no período pesquisado, possibilitando uma leitura das ações cotidianas dos catraieiros. Os romances literários de Manuel de Oliveira Paiva, Gustavo Barroso e Adolfo Caminha são importantes para dar voz aos trabalhadores catraieiros, já que não existe material por eles produzido.

Assim sendo, busca-se apresentar a forma como o espaço da praia foi utilizado pelos trabalhadores portuários, através das metáforas adotadas pelo olhar dos romancistas.

\section{SOBE E DESCE DAS ONDAS: O DIA A DIA DE TRABALHO DOS CATRAIEIROS}

O Porto de Fortaleza localiza-se próximo à antiga Alfândega, onde atualmente está situada a Ponte Metálica na Praia de Iracema, construída em 1904. De início, o porto não

\footnotetext{
${ }^{5}$ Essa documentação não está catalogada e encontra-se sob custódia do Arquivo Público Intermediário do Estado do Ceará.

${ }^{6}$ PAIVA, Manoel de Oliveira. A Afilhada. São Paula: Editora Anhambi, 1961. Publicado inicialmente nas páginas do jornal $O$ Libertador em 1889, descreve a cidade de Fortaleza e as pessoas que nela habitavam em meados de 1870. Caracteriza Fortaleza como sendo uma cidade oceânica.

${ }^{7}$ BARROSO, Gustavo. O Mississipi. Fortaleza. Edição: UFC, Casa de José de Alencar, programa editorial, 1996. Este foi o último livro escrito antes da morte do autor, um dos mais "fecundos escritores brasileiros". Marcado pelo cotidiano da cidade de Fortaleza no final do século XIX, descreve a cidade como tendo a forte característica marítima e das praias; o poço da Draga é marca registrada no autor desde as memórias de infância.

${ }^{8}$ CAMINHA, Adolfo. A Normalista. São Paulo; Martim Claret, 2007, p. 45. Este romance foi publicado em 1893, ou seja, há mais de cem anos. Narra aspectos do cotidiano da cidade de Fortaleza durante o final do século XIX como pano de fundo para a história de Maria do Carmo, a normalista entregue pelo pai para ser criada pelo padrinho.
} 
possuía estrutura para a atracação de navios de grande porte, processando-se o serviço de carga e descarga de mercadorias e passageiros por embarcações de pequena escala.

Os catraieiros eram trabalhadores que realizavam o transporte de mercadorias e passageiros em catraias $^{9}$, ou seja, carregavam e descarregavam os produtos dos navios que ficavam atracados a distância do cais.

No trecho do Dicionário de Termos Populares, o catraieiro era o:

Indivíduo que tripulava os botes no porto de Fortaleza e fazia disso profissão, servindo no embarque e desembarque de passageiros e mercadorias, quando os navios ainda não atracavam a um cais, como atualmente, e ficavam no alto mar, distantes da ponte do desembarque ${ }^{10}$.

Mediante a atividade de frete sobre a água ${ }^{11}$ os catraieiros retiravam o sustento da família, estabeleciam amizades com aqueles que trabalhavam na região portuária e também se divertiam. Porém, havia uma série de dificuldades com o transporte das mercadorias e as complicadas relações com os contratadores da mão de obra; além de o pagamento do frete ser baixo, o catraieiro pagava uma taxa ao Capitão do porto para assegurar a autorização do transporte marítimo.

Os trabalhadores catraieiros dependiam das marés para realizar um trabalho de fundamental importância para a dinâmica da cidade de Fortaleza e do porto, visto que tinham de saber navegar em embarcações de pequeno porte e possuir conhecimentos sobre estas $^{12}$.

Para compreender o cotidiano desses trabalhadores faz-se uso da ideia de experiência de E. P. Thompson a fim de verificar o quanto as vivências são indispensáveis para o processo de autorreconhecimento dos trabalhadores como uma categoria de trabalho. Nesse sentido, a concepção de experiência na identificação desses processos de construção, manutenção, ou até mesmo de transformação dos costumes e das vivências dos

\footnotetext{
${ }^{9}$ Pequeno barco tripulado por um homem.

${ }^{10}$ SERAINE, Florival. Dicionário de termos populares. Revista, ampliada e melhorada pelo autor, 2a ed.; Fortaleza - CE, 1991, p. 97.

${ }^{11} \mathrm{O}$ frete consistia no sistema de contratação da catraia para realização do transporte de mercadorias e passageiros do porto para o navio.

${ }^{12} \mathrm{O}$ catraieiro era o homem que utilizava a pequena embarcação denominada catraia. Esta era, segundo o mesmo dicionário, uma mulher desprovida de atrativos físicos, mulher pública de ínfima classe; mulher destituída de encantos físicos e malvestida, que circulava pela zona portuária. O termo catraieiro foi uma forma de mostrar pejorativamente o quanto esses trabalhadores - catraieiros - eram desvalorizados.
} 
trabalhadores catraieiros no porto de Fortaleza permite compreendê-los no processo de "fazer-se" cotidiano ${ }^{13}$.

\section{OS CATRAIEIROS E O PORTO}

Ao cotejar a descrição do livro A Afilhada com as informações contidas na documentação da Casa Boris, o termo utilizado para designar o tipo de embarcação responsável pelo transporte de mercadorias era "lancha"; já nos jornais Unitário e Jornal do Ceará, a denominação era "catraia" e "catraieiros", quando mencionam a questão da greve ocorrida no fim de 1903 , início de $1904^{14}$. No editorial de $O$ Unitário do dia 4 de fevereiro de 1904, João Brígido afirma que o transporte de passageiros e das mercadorias presentes no vapor “Maranhão" seria realizado por lanchões navegados pelos catraieiros ${ }^{15}$.

Em nota do mesmo jornal foi divulgada a notícia de que "a greve dos catraieiros e lancheiros tomou caráter gravíssimo" ${ }^{16}$, o que levou a pensar que as atividades exercidas por eles eram diferentes. Porém, na edição de 9 de janeiro, João Brígido, ao ressaltar suas ações entre os trabalhadores e os contratadores, anteriores aos embates na praia, afirma:

\footnotetext{
Embora alguma cousa doente, dirigi-me á casa dos Srs. Boris para entender-me com seos trabalhadores, que hesitavam em sair ao mar. Alli encontrei um grupo ao qual pedi de balde para que fizesse o serviço. Todos recusarão como já tinham recusado ao proprio Sr. Achilles Boris, apontando para o quartel de Lopes da Cruz , apinhado de soldados da policia e de linha, pelo frete do qual elles devião passar indo ao lugar das lanchas ${ }^{17}$.
}

Os catraieiros e os lancheiros realizavam os mesmos serviços no porto, porém possuíam denominação diferenciada. Os contratadores, homens responsáveis pelo trabalho de transporte de mercadorias sobre a água, eram chamados de lancheiros. Já a denominação catraieiro, acredita-se ter sido uma autodenominação por parte dos trabalhadores para fazer referência à embarcação por eles utilizada, a catraia.

\footnotetext{
${ }^{13}$ THOMPSON. E. P. A formação da classe operária - A árvore da liberdade: tradução de Denise Bottman. - Rio de Janeiro: Paz e Terra, 1987, p. 9.

${ }^{14}$ Publicações feitas no Jornal Unitário e Jornal do Ceará, com maior intensidade durante o fim de 1903 e o ano de 1904.

${ }^{15}$ UNITÁRIO, Fortaleza. José Gaytoso, 4 de fevereiro de 1904, no 93, p. 1.

${ }^{16}$ UNITÁRIO, Fortaleza. Fortaleza-3, 26 de janeiro de 1904, no 89, p. 1.

${ }^{17}$ UNITÁRIO, Fortaleza. Declaração. 9 de janeiro de 1904, no 82, p. 1.
} 
Através das leituras dos documentos comerciais, pôde-se localizar aproximadamente 21 catraias, porém um número maior de patrões, ou seja, contratadores, devido à existência de dois nomes em diferentes notas para a mesma lancha, como, por exemplo, a Alsace, que realizou transporte para Luiz Camilo Franca $^{18}$ e Antonio Quaresma. Visto que a nota de pagamento não era encaminhada diretamente ao trabalhador, entende-se que estes homens eram os responsáveis pelo carregamento e estavam ligados às casas comerciais da cidade, como a própria Casa Boris, a Holdernes e Salgado, Marques e Cia., dentre outras, que se dedicavam ao serviço de estiva, contratação e fiscalização da mão de obra portuária.

No Porto havia grande lufa-lufa de gente que embarcava e desembarcava simultaneamente, bracejando, falando alto. A maré d'enchente, crispada pela ventania de sudoeste, num contínuo vaivém, alagava o areal seco e faiscante. Muita gente ao embarque do Conselheiro. Curiosos de todas as classes, trabalhadores aduaneiros de jaqueta azul, guardas d'Alfândega e oficiais de descarga com ar autoritário, de fardeta e boné, marinheiros da Capitania, confundiam-se numa promiscuidade interessante. Jangadeiros arregaçados até aos joelhos, chapéu de palha de carnaúba, mostrando o peito robusto e cabeludo, iam armando a vela das jangadas. A cada fluxo do mar havia gritos e assobios. Maior alvoroço! Jangadas iam e vinham em direção ao Nacional que tombava como um ébrio, aproado ao vento. Apenas quatro navios mercantes, pintadinhos de fresco na popa d'uma barca italiana - "Cívica Vecchia".

O vapor apitou pedindo mala. Era uma maçada ir a bordo com a maré cheia e um vento como aquele. Demais o sol estava de rachar $^{19}$.

A maioria dessas embarcações ou catraias tinha nomes franceses, o que pode ser explicado pela influência dos irmãos Boris, pelo fato de serem os proprietários das lanchas, levando-nos à conclusão de que seus proprietários eram os armadores ${ }^{20}$ ou contratadores, e os trabalhadores apenas utilizados como mão de obra.

O agente contratado pela empresa de navegação, responsável pela contratação da mão de obra avulsa do porto e pela fiscalização do processo de carregamento dos navios, era chamado "patrão" e prestava serviço para os armadores ligados à empresa de navegação.

Nas notas comerciais de pagamento de trabalhadores consta o nome do mesmo patrão para várias lanchas, como no caso de Luiz Camilo França, que no dia 24 de março de 1904 recebeu pagamento pelo transporte de mercadorias nas lanchas Aurora, Loraine e

\footnotetext{
${ }^{18}$ Nota de pagamento de trabalhadores do armazém. Casa Boris, 25 de março de 1904.

${ }^{19}$ CAMINHA, 2007. Op. cit., p. 45.

${ }^{20}$ As grandes empresas de navegação possuíam em cada porto do país os seus armadores, homens responsáveis pela contratação de toda a mão de obra necessária para o serviço de carga e descarga dos navios.
} 
Asará, recebendo a primeira, 40.000 mil réis, e as demais, 20.000 mil réis. Nesse documento também se constata que cada lancha pagava 5.000 mil réis como passagem ${ }^{21}$. A fim de obter autorização para realizar o transporte, precisava-se pagar ao homem responsável pela organização e fiscalização do carregamento dos navios (contratador) a parte do que recebia pelo trabalho.

O transporte deveria ser realizado de acordo com a capacidade da embarcação, e no caso da inobservância da quantidade de volumes, o patrão realizaria reclamações, pois este era responsável pela segurança do carregamento.

O pagamento para cada viagem variava entre 3.000 e 20.000 mil réis, dependendo da capacidade de volumes que a lancha comportasse. Existem registros de pagamentos efetuados que ressaltam a não existência de reclamações devido à quantidade de carregamento em excesso, como no caso da Lancha Paris, que transportou " 219 volumes de carga sem reclamação da parte da mesma"22, e da Lancha Saverne, que transportou 165 volumes de carga também sem reclamação ${ }^{23}$. Porém, deve-se ressaltar que o número de volumes para cada lancha variava de acordo com a capacidade de cada embarcação e o tipo de produto transportado.

A questão da capacidade do transporte pode ser percebida no caso da lancha Pará, com capacidade menor que as lanchas Aurora e Louraine, que teria diminuído o número de viagens, segundo nota: "deve ser pago somente $31 / 2$ lanchas à capatazia, no entanto, esta lancha carregou completa" ${ }^{24}$. Em outras palavras, o responsável pela fiscalização e contratação da lancha Pará não receberia o pagamento pelo número de viagens realizadas, já que o contratador deveria ter solicitado uma lancha com maior capacidade e, assim, diminuir os gastos.

A partir dos indícios encontrados nesses documentos, pode-se compreender a difícil condição dos catraieiros, visto que os trabalhadores, além de enfrentarem a adversidade das marés, precisavam de um contratador e corriam o risco de não receber o pagamento completo, porque pagavam parte do que recebiam quando da compra da passagem (autorização) para fazer o transporte.

\footnotetext{
${ }^{21}$ Cf. Nota de pagamento de trabalhadores do armazém. Casa Boris, 24 de março de 1904.

${ }^{22}$ Cf. Nota de pagamento de trabalhadores do armazém. Casa Boris, 24 de maio de 1904.

${ }^{23}$ Cf. Nota de pagamento de trabalhadores do armazém. Casa Boris, 12 de abril de 1904.

${ }^{24}$ Cf. Nota de pagamento de trabalhadores do armazém. Casa Boris, 24 de março de 1904.
} 
A condição de vida dos catraieiros estava em declínio: trabalhavam muito, recebiam pouco. Devido à construção do novo porto, o trabalho dos catraieiros diminuiu, com um novo cais de formato retilíneo e a destruição dos antigos trapiches e pontes permitindo a atracação dos navios ao cais. Além da precária situação de trabalho, os catraieiros também precisavam lidar com as determinações abusivas do Capitão do porto, Lopes da $\mathrm{Cruz}^{25}$, que realizava cobrança de taxas indevidas aos pescadores e catraieiros.

O jornal O Unitário assim relatou o fato:

...publica e notoria a sua habilidade em surripiar moeda, cobrando aos pobres pescadores e catraeiros impostos demasiados, de cujos excessos apoderava-se clandestinamente, ao mesmo tempo em que lesava o próprio thesouro nacional ${ }^{26}$.

Essa situação se repete em outros locais no Brasil. As condições materiais e as adversidades do trabalhador portuário, e as suas consequências na vida familiar, são analisadas por Maria Lucia Caira Gitahy:

O trabalhador do porto vivia perto do local de trabalho e seu ritmo de trabalho, no mínimo irregular, permitia a ele ir e vir de casa para o porto mais de uma vez por dia. A rotina de trabalho das esposas dos trabalhadores do porto era diretamente afetada pelas horas que seus maridos trabalhavam e pelo tipo de carga com que eles estavam lidando. Os filhos sabiam muito sobre o trabalho dos pais e, morando junto ao porto, observavam os navios chegando e partindo. As flutuações dos salários do trabalhador do porto tinham um óbvio impacto no orçamento da família ${ }^{27}$.

Em vários pontos percebem-se as semelhanças entre a descrição acima e a dinâmica (trabalho - casa) dos trabalhadores catraieiros e suas consequências no cotidiano de suas famílias, como a dura atividade de trabalho e o dinheiro incerto. No caso de Fortaleza, a maioria dos trabalhadores portuários morava no bairro do Oiteiro, próximo à região do Porto, local marcado pelos casebres, pela pobreza e pela negligência da oligarquia acciolina.

Raimundo Girão descreve este local: “... fomos ao Oiteiro, onde chácaras de luxo defrontavam com a casaria pobre dos pescadores e catraieiros...". Tal localidade ficava

\footnotetext{
${ }^{25}$ O Capitão Lopes da Cruz esteve no comando do porto de Fortaleza durante o período da greve dos catraieiros, porém foi exigida sua saída após o dia 3 de janeiro de 1904, devido à repercussão negativa da repressão aos grevistas.

${ }^{26}$ UNITÁRIO, Fortaleza. Ao público, 27 de fevereiro de 1904, no 103, p. 1.

${ }^{27}$ GITAHY, Maria Lucia Caira. Ventos do Mar. Trabalhadores do Porto, movimento operário e cultura urbana em Santos, 1889-1914. Editora da Universidade Estadual Paulista: São Paulo 1992, pp. 121-122.
} 
próximo à Rua de Baixo e à Rua das Flores, a qual também facilitava o acesso à Praça da Sé e ao local dos armazéns e da região portuária ${ }^{28}$.

No romance $A$ Afilhada, o Oiteiro é assim descrito:

...uma zona irregular e caprichosa de alegrias da vegetação, entre o mundo da cidade e o vasto aldeamento dos pescadores, dos lancheiros, dos trabalhadores da praia, dos homens da praia, dos homens do ganho, dos operários e de uma numerosa população decaída, habitando cabanas, verdadeiras covas de palhas desses esquimós do areal ardente... ${ }^{29}$

E mais:

...era um "bairro original e paupérrimo", com uma "população rareada, de gente pobre, transitava ali na subida, a maior parte recolhendo da feira. Passam quase todos pelo patamar da Sé, com os seus urus manteúdos, pés descalços, peito ao vento, xale trespassado, satisfeitos com eles mesmos ${ }^{30}$.

Ao se observar a localidade do Oiteiro e suas adversidades, podem-se perceber as condições materiais dos trabalhadores catraieiros e as experiências de luta para superar as dificuldades cotidianas e ter o mínimo de condições para sobreviver.

Analisando o cotidiano de trabalho dos catraieiros, busca-se entender o processo de organização do seu "fazer-se" enquanto categoria profissional. Mediante o conceito de classe operária, E P. Thompson afirma que as relações de classe e a consciência são formações culturais, e a classe em si mesma não é uma "coisa" e sim um "acontecer" 31 .

\footnotetext{
${ }^{28}$ GIRÃO, Raimundo. Fortaleza e a Crônica Histórica. Casa José de Alencar. Programa editorial, edição especial, 2000, p. 34.

${ }^{29}$ PAIVA, op.cit., p. 26.

${ }^{30}$ Idem.

${ }^{31}$ THOMPSON, 1998. Op. cit., p. 10.
} 


\section{AS RELAÇÕES DE TRABALHO ENTRE CONTRATADORES E CATRAIEIROS}

“Navio parado não pega frete e tem prejuízo." ${ }^{32}$

De início, o que parece mais perceptível na relação de trabalho dos catraieiros com os contratadores é a tensão existente entre eles. De um lado, estavam os contratadores responsáveis pelo contrato de mão de obra avulsa para a carga e descarga dos navios e que também mantinham relações com as Casas Comerciais, como Boris Frères, Holdernes \& Salgado, as quais mantinham ligações com as grandes empresas de navegação. Do outro, estavam os catraieiros, trabalhadores avulsos, que sofriam as duras cobranças dos patrões e a relação de dependência a vários contratadores. Tratava-se de uma atividade marcada pela instabilidade, visto que era um trabalho ocasional e dependente das condições do mar, da chegada e saída dos navios, além de que poderiam ser ou não escolhidos na "parede" a contratação. Além desses fatores, era hábito do catraieiro trabalhar durante o dia todo e conseguir o dinheiro que precisava para suas necessidades mínimas, voltando a trabalhar somente quando necessário.

A relação de tensão ocorria entre os trabalhadores e os contratadores por causa de interesses divergentes, já que os catraieiros realizavam a atividade de transporte de mercadorias a fim de retirar o sustento da sua família, mesmo de maneira insuficiente, e aceitavam as condições materiais precárias, enquanto os contratadores exigiam agilidade no serviço para aumentar os lucros e pressionavam os trabalhadores.

Maria Cecília Velascos Cruz analisa a dinâmica de contratação da mão de obra dos portos, a partir da qual podemos verificar a semelhança com o que ocorria no porto de Fortaleza:

Os portos são quase sempre marcados por uma terceira característica geral de grande importância para a cristalização da forma de contratação da mão-de-obra: eles são palco de um choque fundamental de interesses entre seus proprietários, exploradores e/ou administradores e seus principais usuários - os armadores. A raiz do conflito é fácil de ser percebida. Ao proprietário ou exportador do porto interessa maximizar a renda oriunda do uso de suas instalações ou serviços, mediante a cobrança de taxas sobre a tonelagem dos navios, tempo de atracação,

\footnotetext{
${ }^{32}$ SILVA, Fernando Teixeira da Silva. Operários sem patrões: os trabalhadores da cidade de Santos no entreguerras. Campinas, SP: Editora da Unicamp, 2003, p.178.

${ }^{33}$ Idem. Op. cit., p. 136.
} 
trânsito de mercadorias, armazenagem, utilização dos maquinismos do cais, fornecimento de água, lastro, etc. Ao armador, pelo contrário, interessa minimizar os custos acima e agilizar ao máximo a passagem do navio pelo porto, carregando e descarregando o mais rápido possível ${ }^{34}$.

A tensão entre as partes aqui analisadas era inevitável, porque ambas eram cobradas, dentro das suas funções, pelas grandes empresas de navegação, e obviamente os trabalhadores avulsos ficavam à mercê dos contratadores que, muitas vezes, eram destacados comerciantes da cidade.

No caso do porto de Fortaleza, ocorria um sistema no qual os grandes armadores nacionais, como a Lloyd Brasileira, Companhia Nacional de Navegação Costeira, Companhia de Comércio e Navegação, trabalhavam com o sistema de estiva indireta, ou seja:

...tinham sua estiva contratada por empreiteiros que se obrigavam a agir como
contratantes da mão-de-obra, pagando as despesas relativas a taxas portuárias e
avarias, tendo ainda que fornecer todo material necessário à segurança e ao
transporte nas embarcações ${ }^{35}$.

O sistema de contratação dependia da chegada dos navios, e isso contribuía para a dispersão dos trabalhadores, já que os grupos contratados para o embarque e desembarque não eram fixos. A escolha dos trabalhadores era marcada pela turbulência gerada pelos trabalhadores que se aglomeravam ao redor do contratante, em busca do trabalho de regime ocasional, além de tentarem se destacar para chamar atenção, fosse pelas características físicas, fosse pelas relações de trocas de favores ou apadrinhamentos. As relações estabelecidas entre os catraieiros e contratadores na "parede" ultrapassavam os limites da contratação, pois nesse local ocorriam conversas sobre política, encontros estáveis que fortaleciam os laços de solidariedade e o aumento da capacidade de mobilização ${ }^{36}$.

A solidariedade era importante na vivência dos trabalhadores portuários, uma vez que compartilhavam muitas dificuldades no tocante à exploração no trabalho, às formas de contratação e de pagamento. Os laços de amizade e interesses poderiam existir entre

\footnotetext{
${ }^{34}$ CRUZ, Maria Cecília Velascos. "Virando o Jogo: estivadores e carregadores no Rio de Janeiro da Primeira República." Tese de Doutorado defendida no programa de pós-graduação em Sociologia da Faculdade de Filosofia e Letras e Ciências Humanas da Universidade de São Paulo, São Paulo, 1998, p. 38.

${ }^{35}$ SILVA, 2003. Op. cit., p. 170.

${ }^{36}$ Idem. Op. cit., p. 153.
} 
trabalhadores de ofícios diferentes, devido à proximidade entre os catraieiros e os pescadores, como se pode perceber no telegrama divulgado na segunda página de $O$ Unitário, do dia 26 de janeiro:

Fortaleza - 4

O sorteio para a armada procedido entre os matriculados na Capitania do Porto no dia 29 do passado occasionou a declaração da greve geral dos homens empregados na pescaria e no trafego do porto.

Hoje a chegada do vapor Maranhão todos se recusaram a fazer o serviço de embarque e desembarque de passageiros e cargas $^{37}$.

Os laços de solidariedade foram estreitados em decorrência da necessidade comum dos portuários de lutar contra o processo de recrutamento. Assim, no jornal O Unitário, de dia 30 de dezembro de 1903, Hermenegildo Firmeza convocou os pescadores ${ }^{38}$ a resistir ao processo injusto de recrutamento e os aconselhou a não obedecerem e se oporem à "lei do recrutamento, que nem sequer respeita os direitos que o antigo recrutamento militar garantia" 39 .

Os transtornos causados aos contratadores, quando ocorriam problemas no processo de carga e descarga dos navios, levaram a embates entre os catraieiros e contratadores durante a greve 1903-1904. Na manhã do dia 3 de janeiro de 1904, os catraieiros, em protesto ao sistema de sorteio e alistamento para a Armada da Marinha, se negaram a realizar o desembarque dos "300 passageiros do navio Maranhão, sendo 50, de primeira classe e os demais, de terceira, tiveram de ficar presos a bordo, sem possibilidade de vir para terra, à falta de condução" ${ }^{40}$.

O navio permaneceu ao largo, os passageiros ficaram impossibilitados de sair e as mercadorias não foram descarregadas, o que ocasionou prejuízos aos contratadores. Possivelmente, essa foi a intenção dos catraieiros: atacar o "ponto fraco" dos seus patrões, para assim conferir visibilidade ao que reivindicavam.

\footnotetext{
${ }^{37}$ UNITÁRIO, Fortaleza. Telegrammas, 26 de janeiro de 1904, no 85, p. 4.

${ }^{38}$ Entendemos que devido ao conhecimento prático sobre o mar, os pescadores também realizavam o serviço de transporte de mercadorias e passageiros sobre a água nas chamadas catraias.

${ }^{39}$ UNITÁRIO, Fortaleza. Recrutamento da Marinha. 30 de dezembro de 1903, no 77, p. 1.

${ }^{40}$ MENEZES, Raimundo de. Coisas que o tempo levou. Fortaleza: Edésio Editor,1938, pp. 120-121.
} 
Por mais que os contratadores fossem de certo modo a favor da insatisfação dos trabalhadores, em relação à Lei de Sorteio Militar não era interessante para os empregadores manifestações que prejudicassem de imediato seus lucros.

O episódio do dia 3 de janeiro e os efeitos negativos da greve para a economia da cidade não foram motivos de preocupação somente para os contratadores e redatores de $O$ Unitário, mas também causaram preocupação ao Governo do Estado e à Associação Comercial, que promoveram uma reunião extraordinária, no dia 4 de janeiro de 1904, para analisar a situação do serviço de embarque e descarga de mercadorias, após os graves acontecimentos do dia anterior. A reunião contou com a presença do presidente da Associação, Dr. Thomas Pompeu, do secretário Dr. Alfredo Severino, e também do Presidente do Estado ${ }^{41}$.

Em nota, para contestar o transtorno ocorrido durante a chegada ao porto do navio Maranhão, um passageiro descreveu o episódio da praia, publicado na primeira página de $O$ Unitário. Afirmou ter sido lamentável o fato e destacou a cobrança de taxas para a realização do desembarque: "Eu paguei $22 \$$, e houve quem pagasse $50 \$, 100 \$$ e até $200 \$$ afora o carreto dos baús e denúncia que parte do dinheiro foi para o Sr. José Gaytoso” ${ }^{42}$. A greve continuou por mais alguns dias após o 3 de janeiro, mesmo diante das pressões e da repressão do Governo para que o trabalho fosse normalizado, o que gerava medo aos trabalhadores.

Os catraieiros, embora submetidos ao sistema de disciplina de diferentes empresas, possuíam maiores possibilidades de enfrentamento direto com os contratadores. Dessa maneira a questão do alistamento foi o estopim para que os trabalhadores lutassem contra os abusos dos contratadores e do Governo.

Na edição do dia 26 de janeiro de 1904, assim como em várias outras publicações, os redatores de $O$ Unitário, e também os advogados, chamavam a atenção dos que não compareceram ao escritório de João Brígido para solicitarem o habeas corpus. O Jornal listou

\footnotetext{
${ }^{41}$ UNITÁRIO, Fortaleza. Associação Comercial, 16 de janeiro de 1904, no 85, p. 4.

42 UNITÁRIO, Fortaleza. José Gaytoso, 4 de fevereiro de 1904, no 93, p. 1. José Gaytoso era procedente do Estado do Amazonas; no dia seguinte ao 3 de janeiro, segundo escrito no Unitário, realizou especulações e se aproveitou da situação calamitosa do porto para ganhar dinheiro, e também buscou proteger seu amigo, o Capitão Lopes da Cruz.
} 
os contemplados com esta ação, concedida no dia anterior para os sorteados, mencionando também os que não obtiveram o referido direito ${ }^{43}$.

O apoio não ocorreu somente através de ações jurídicas, já que o jornal $O$ Unitário também realizou denúncias no tocante às cobranças de taxas indevidas pelo Capitão do porto aos trabalhadores e às disputas daquele com alguns contratadores.

Um fato relevante, divulgado no dia 16 de janeiro de 1904, foi o destaque dado pelo jornal à intimação realizada pelo capitão do porto de Fortaleza, obrigando os agentes da Companhia Inglesa de Vapores, senhores Holdernes e Salgado, a retirar as guaritas de madeira. Essa ação demonstra a tensão existente, também, entre os contratadores e o Capitão Lopes da Cruz:

O capitão do porto Lopes da Cruz havia mandado intimar aos agentes da Companhia de vapores inglezes nesta praça, os negociantes, Holdernes e Salgado, para retirarem umas guaritas, ou casas de madeira, que possuem na praia para o trabalho do pessoal da sua agencia e onde têm carteira, livros, papeis etc., necessários ao serviço dos vapores.

Para semelhante absurdo invocou o Capitão do Porto o facto de prejudicarem aquellas guaritas á fiscalização do serviço da alfândega.

O Inspector d'esta informou em sentido contrario, e Holdernes e Salgado pediram um mandato de manutenção ao juis seccional, o qual foi concedido.

O Sr. Lopes está mesmo uma fera, querendo bulir com todo o mundo.

Ah macacão!...

Só é de lastimar-se que sahindo tão já do Ceará, não encontre quem lhe dê uns murros na sua larga queixada e dentuça amarella de feio ${ }^{44}$.

Em alguns momentos a relação entre os contratadores e o Capitão do porto era difícil $^{45}$, como no caso dos Senhores Holdernes \& Salgado, pois havia interesses comerciais, sendo os serviços e os lucros dos comerciantes e contratadores comprometidos pelas ações de Lopes da Cruz.

As páginas do jornal $O$ Unitário destacaram a ideia de que os catraieiros eram explorados com a cobrança de taxas ilegais pelo Capitão Lopes da Cruz, mas não abordam as condições de pobreza dos catraieiros, que eram agravadas não somente pelas cobranças de

\footnotetext{
${ }^{43}$ UNITÁRIO, Fortaleza. Habeas Corpus, 26 de janeiro de 1904, no 89, p. 2.

${ }^{44}$ UNITÁRIO, Fortaleza. Habeas Corpus, 26 de janeiro de 1904, no 85, p. 4.

${ }^{45}$ A relação de trabalho entre os comerciantes, seus contratadores e o Capitão do porto era ditada pela tensão, pois Lopes da Cruz também tomava decisões, como cobranças de taxas de embarque e desembarque, que iam ao encontro dos interesses dos grandes comerciantes e das casas comerciais.
} 
taxas indevidas, bem como pela exploração do trabalho por parte dos armadores. Porém, estes colaboradores do jornal estavam próximos aos oposicionistas da oligarquia acciolina ${ }^{46}$.

Assim, Godofredo Maciel, João Brígido, Agapito Jorge dos Santos, Valdemiro Cavalcante, Hermenegildo Firmeza e outros, apesar de criticarem o processo de alistamento que atrapalhava os interesses econômicos dos contratadores, na sua maioria também comerciantes, não denunciavam o péssimo tratamento que estes dispensavam aos trabalhadores do mar.

\section{CONSIDERAÇÕES FINAIS}

Através da análise dos jornais da época e da documentação comercial foi possível compreender os fatores motivadores da mobilização dos catraieiros para a greve, a partir das relações de trabalho, abordando as relações existentes entre trabalhadores e empregadores, visualizando as ações dos catraieiros diante das adversidades cotidianas, bem como ante a exigência de rapidez e qualidade do transporte das mercadorias pelos contratadores, de modo que foi identificada a tensão entre esses personagens.

A greve dos catraieiros foi mais que uma reação aos abusos dos contratadores. Embora aceitassem as opressivas condições de trabalho, a greve foi motivada de forma imediata pela necessidade de fugirem ao processo de alistamento e sorteio para a Armada, ultrapassando assim a tensa relação patrão/empregado. Com a Lei de Recrutamento, os trabalhadores se defrontaram com um problema imediato, problema este que não era mais somente dos catraieiros, mas também dos contratadores, visto que estes perderiam mão de obra e teriam seus lucros ameaçados ${ }^{47}$.

A greve organizada pelos trabalhadores catraieiros no Porto de Fortaleza pode ser compreendida como um "fenômeno histórico que integra acontecimentos díspares e aparentemente sem conexão, tanto na matéria-prima da experiência quanto na consciência" ${ }^{48}$, sendo resultado da trajetória desses trabalhadores.

\footnotetext{
${ }^{46}$ UNITÁRIO, Fortaleza. Ao Público, 27 de fevereiro de 1904, no 103, p. 1.

${ }^{48}$ ARRUDA, José Robson de Andrade. Experiência de classe e experimento historiográfico em E. P. Thompson. Revista Projeto e História: Revista do Programa de Estudos Pós-Graduados em História da PUC-SP. São Paulo, vol. 12, 1995, p. 96- 97.
} 
Nessa perspectiva, a experiência guarda relação direta com a cultura dos trabalhadores, suas ações no dia a dia, as relações econômicas e sociais existentes entre os catraieiros, os quais, como uma categoria profissional, estavam num processo de autoconhecimento e se identificavam por meio das relações de trabalho, e até mesmo de dificuldades materiais afins.

Recebido em 21/12/2009

Aprovado para publicação em 12/05/2010 